Tempo Social; Rev. Sociol. USP, S. Paulo, 12(1): 165-186, maio de 2000.

\title{
Identidades sindicais europeias em tempos de globalização
}

\author{
HERMESAUGUSTO COSTA
}

RESUMO: Recuperando alguns exemplos da realidade sindical europeia, este texto propõe-se elaborar, em primeiro lugar, uma síntese de algumas transformações contemporâneas ocorridas no mundo laboral. Em segundo lugar, passa em revista alguns dos traços característicos da(s) crise(s) actuais do sindicalismo, traços esses que têm dificultado a criação de uma coesa identidade sindical europeia. Por fim, são recuperados alguns temas em redor dos quais se poderão pensar futuros desafios alternativos e maximizar uma (re)afirmação identitária do trabalho.

\section{Introdução}

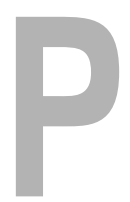

ercorrer a agenda das preocupações e problemas que afectam o sindicalismo mundial contemporâneo constitui um exercício que há mais de duas décadas vem despertando o interesse de académicos que se dedicam ao estudo destas questões. $\mathrm{O}$ avolumar de publicações neste domínio têm revelado, em muitos casos, uma clara orientação para a descrição de cenários de futuro pouco auspiciosos para o sindicalismo. Em todo o caso, mesmo que em reduzido número, é de admitir a existência de movimentos contra-hegemónicos gizados pelos actores do campo laboral como forma reactiva face aos processos de globalização da economia em curso. $\mathrm{O}$ reconhecimento suscitado a partir do interior do próprio movimento sindical de que são possíveis as alternativas, a começar, desde logo, pelo reconheci-
UNITERMIOS:

sindicalismo, globalização, identidades sindicais.

Neste texto foi mantida a escrita original, em português de Portugal (Nota do Editor).

Professor da Faculdade de Economia da Universidade de Coimbra 
Este texto recupera parte da argumentação desenvolvida pelo autor em trabalhos anteriores (Costa, 1997; 1998) a propósito dos desafios colocados ao sindicalismo na "era da globalização". Incorpora igualmente elementos de uma investigação realizada no Centro de Estudos Sociais no âmbito do projeto de investigação "O movimento sindical português perante os desafios da globalização" (PRAXIS PCSH/P/SOC/118/96, financiado pela JNICT).

O autor agradece a Leonardo Mello e Silva os comentarios e sugestões que fez a uma primeira versão deste trabalho. mento de que existem fraquezas, será por certo uma das formas de superar a tentação para sucumbir ao problema das soluções e procurar exercitar sem receios a solução dos problemas.

Este texto não reproduz, também ele, uma visão muito optimista das novas opções que se colocam ao trabalho (e em especial ao sindicalismo) neste final de século. Em todo o caso, nele se reunem um conjunto de contributos cujo interesse analítico pode revelar-se útil para o sindicalismo do século XXI. Embora grande parte das situações descritas se reportem ao contexto europeu (e dentro deste ao português), a referência às mesmas poderá constituir um importante exercício reflexivo para o sindicalismo em geral e uma forma de projectar, mesmo por entre múltiplas contrariedades, um futuro mais risonho, porque possível de alcançar.

Dividido em três partes principais, este texto começa por recuperar algumas transformações contemporâneas associadas ao mundo do trabalho, em particular as resultantes dos processos de globalização da economia e dos impactos por estes provodados no mundo laboral. Numa segunda parte, e como prolongamento ou corolário de tais impactos, são passados brevemente em revista certos traços característicos da(s) crise(s) do sindicalismo europeu contemporâneo, os quais são responsáveis pela dificuldade em edificar uma coesa identidade sindical europeia. Por fim, e na linha de alguns dos debates académicos actuais, são recuperadas algumas das questões em redor das quais se podem pensar desafios sindicais alternativos. Cada uma dessas questões/ desafios faz-se acompanhar de exemplos que servem não só para confirmar as dificuldades que lhes estão associadas, mas que em simultâneo devem ser maximizadas como formas de (re)afirmação identitária do trabalho.

\section{Sinais dos tempos e dos impactos}

A segunda metade do século XX patenteou claros sinais de intensificação dos processos de transnacionalização económica. O valor da produção total dos países industrializados cresceu, entre 1964 e 1992, a uma taxa média de 9,0\% ao ano, ao passo que o valor das exportações desses países cresceu a uma taxa média de $12,0 \%$ e, por sua vez, os pedidos e concessões de empréstimos bancários para além das fronteiras nacionais cresceram ainda mais rapidamente, situando-se na casa dos $32,0 \%$ ao ano (cf. Aaron et alii, 1995, p. xi). Se procedermos a uma análise por décadas, verificamos que após o crescimento económico e o aumento da produtividade mundiais que marcaram os anos sessenta, a década de setenta significou, porém, o início do abrandamento dessa evolução favorável, transportando para as décadas de oitenta e mesmo de noventa muitos dos sinais de desaceleração económica, ainda que esses sinais tenham apresentado um grau de intensidade diferenciada pelo mundo fora. Apesar disso, a década em que vivemos está sobretudo a confirmar a tendência para a crescente globalização dos mercados já registada no decénio precedente, confirmando assim o peso da "escala global". O co- 
mércio financeiro mundial estimulou a multiplicação das empresas transnacionais que actuam não só em função das economias de muitas regiões do mundo, como contribuem directamente para a globalização do mercado por via dos seus investimentos directos estrangeiros (prioritariamente na América do Norte, Europa ou Ásia, mas também, cada vez mais, noutras regiões do globo como a América Latina). Por exemplo, ao longo da segunda metade da década de oitenta, em países como Itália e Portugal, o investimento americano directo cresceu mais de $150,0 \%$ e mais do que duplicou em Luxemburgo, França, Holanda, Irlanda e Espanha (cf. Erikson \& Kuruvilla, 1995, p. 50). Por seu lado, entre os anos de 1983 e 1989 as exportações mundiais cresceram $9,4 \%$ ao ano e o crescimento médio anual do produto interno bruto foi de $7,8 \%$, ao passo que o investimento directo estrangeiro cresceu 28,9\% ao ano (cf. Grupo de Lisboa, 1994, p. 58-59).

Tendo-se apoiado, na sua fase contemporânea, em instituições promotoras do comércio e investimento estrangeiros - tais como o sistema de Bretton Woods que vigorou desde o final da Segunda Guerra Mundial até 1973 ou as negociações do GATT, iniciadas nos anos cinquenta (e destinadas a reduzir tarifas e outras barreiras ao comércio internacional) -, a globalização revela-se capaz, através da sua propensão aglutinadora, de destapar tendências comuns. Do ponto de vista sindical, uma dessas tendências comuns é simultaneamente um medo comum: o medo que os diferentes movimentos sindicais nacionais expressam de que a globalização lhes está a cortar pela raiz as suas capacidades de negociação e de influência política. Este efeito negativo da globalização sobre o sindicalismo é testemunhado pela competição resultante das produções de baixo custo que exercem pressão de sentido descendente (race to the bottom) sobre os salários e o emprego em indústrias como a têxtil ou do vestuário. Procurando assegurar vantagens competitivas, os empregadores investem frequentemente na produção de bens e serviços tecnologicamente mais intensivos (que incorporam mais tecnologia), o que, no curto prazo, pode trazer consequências nocivas para os sindicatos visto que "reduz a procura de trabalhadores manuais - que constituem uma grande parte de muitos movimentos laborais - enquanto impulsiona o emprego dos trabalhadores não manuais" (Jacoby, 1995, p. 8).

No passado, o capital encontrava-se mais predisposto a aceitar a negociação colectiva sempre que os sindicatos concordassem em "retirar" (moderar) das suas agendas (pela competição) as reivindicações salariais. Tal situação fazia sentido na medida em que os mercados eram fixados dentro de parâmetros nacionais, o que, no fundo, nos confrontava com um capital menos volátil. No presente, porém, com a globalização crescente dos mercados, os sindicatos têm pela frente a difícil tarefa de harmonizar salários para além das fronteiras nacionais. Este facto contribui para enfraquecer a posição do trabalho face ao capital, pois este encontra-se agora mais predisposto a proceder a relocalizações. A "aposta" nestas cria condições intimidatórias para a esfera do trabalho e, consequentemente, fragiliza capacidade negocial dos seus representantes. 
1 Outros rótulos como americanização, imperialismo cultural ocidental ou cocacolonização são igualmente reveladores da faceta homogeneizadora da globalização (cf. Waters, 1995, p. 140).

Em The McDonaldization of Society (1993), G. Ritzer baseia-se numa das mais sólidas teorias sociológicas clássicas: a teoria da racionalização de Max Weber. Ao fazêlo, mostra-se interessado em apontar e alertar para os efeitos perversos (porque desumanizadores e despersonalizadores de relações sociais) desta nova racionalidade que, parafraseando Weber (1990), designa por "iron cage of McDonaldization" (gaiola de ferro da McDonaldização). Como diria Sousa Santos (1995b, p. 262), estamos perante um localismo globalizado que, sendo hegemónico por excelência, parece ter como efeito mais visível uma substituição da aparente soberania do consumidor pelo seu progressivo conformismo. Assinale-se ainda que a argumentação de Ritzer é confirmada em The McDonaldization Thesis (1998), obra onde denuncia a intensificação das irracionalidades associadas à McDonaldização em-
A crise generalizada dos Estados-Providência e das formas de bemestar que lhe estão associadas produz igualmente reflexos sobre o sindicalismo, abalando irrepreensivelmente a imagem de prosperidade social, assim como as atitudes favoráveis que o período do pós-guerra fizera florir. Perante um cenário de ensaio de recuperação de uma política keynesiana a nível global em que os capitalistas não produzem para um "mercado interno" mas sim para um mercado global, sendo que, portanto, os consumidores dos seus produtos não são os seus trabalhadores -, deixa de haver garantias que os trabalhadores, de forma organizada, apliquem os seus rendimentos em produtos fabricados “em casa”. Na prática, e por efeito da globalização, assiste-se a um enfraquecimento das estratégias keynesianas e à correspondente deterioração do poder de negociação da esfera laboral.

Como se foi já deixando antever, além de reflectir o carácter actual da globalização, a transnacionalização das empresas constitui um motivo importante para a procura de esforços correspondentes do ponto de vista laboral. Se é certo que o capital é tendencialmente mais móvel que o trabalho e que este historicamente sempre esteve mais vinculado aos espaços nacionais, tal não significa que não se possam "medir" os efeitos desestruturadores da globalização (em especial de tipo económico) sobre o mundo do trabalho. Vejamos então alguns desses impactos.

Um dos efeitos mais imediatos da globalização sobre o trabalho é detectável através do consumo, em especial se se atentar que cada vez mais se fazem convergir gostos e estilos de vida à escala global. O consumo de determinadas marcas ou produtos - como a Coca-Cola, os Levi's jeans, a Sony, a Toyota, entre outras - é bem exemplificativo dessa tendência. George Ritzer (1993) fala mesmo numa McDonaldização da sociedade ${ }^{1}$ para se dar conta que a estrutura burocrática, durante muito tempo julgada modelo último de racionalização, está a ser substituída pelo restaurante de fast-food (de que a McDonald's constitui um modelo emblemático), o qual não só revolucionou completamente o negócio dos restaurantes na sociedade americana como em todo o mundo ${ }^{2}$. No entanto, a lógica global que o consumo dá mostras de propiciar ou que através dela se parece poder aceder é acompanhada por uma descoincidência entre duas figuras que, sendo a mesma, não o são: a figura do consumidor e a figura do trabalhador. Ou seja, ainda que muitos consumidores sejam simultaneamente trabalhadores, a contradição reside no facto de que enquanto que os primeiros (e os produtos do mercado) são crescentemente globais, os segundos (e os mercados de trabalho) não o são. Trata-se de um paradoxo que não pode ser esquecido, ainda que, como recorda Jacoby (1995), alguma literatura sobre a globalização possa obscurecê-lo, ao tratar os cidadãos como consumidores (pois nessa condição os benefícios da globalização parecem ser mais palpáveis) em vez de os considerar como trabalhadores (condição mais comummente associada às incertezas do que aos benefícios). Como defende Paul du Gay (1996, p. 78), actualmente são os próprios trabalhadores que são encorajados a olhar para o trabalho como consumidores, pois o traba- 
lho tornou-se num espaço em que as pessoas estabelecem relações de consumo para elas mesmas e em que desenvolvem um estilo de vida que maximiza a vontade da existência delas mesmas. Portanto, "enquanto actividade, o trabalho é re-imaginado através da linguagem da cultura do consumidor".

Um spot publicitário a que recorremos é ilustrativo daquele paradoxo em torno das figuras do consumidor e do trabalhador. Referimo-nos a um anúncio da Benetton amplamente divulgado em Portugal em 1996: o que projectava corações de várias cores - white, black, yellow (branco, negro e amarelo) - pretendendo fazer passar a mensagem de que a diversidade se apresentava totalmente irrelevante perante a possibilidade de se consumirem produtos da Benetton. Daí, pois, a expressão united collors (cores unidas, lema que tem acompanhado esta multinacional). No entanto, se a imagem que se projecta é a imagem da igualdade do consumidor perante um determinado produto, o mesmo já não se passa do ponto de vista dos trabalhadores da própria Benetton. Isto é, se "aplicarmos" os três corações aos trabalhadores da Benetton provavelmente seremos levados a concluir que os trabalhadores do Norte de Itália têm uma "cor" muito diferente dos da Tunísia, Argélia, ou Marrocos que também trabalham para essa multinacional. Desse modo, a uniformização que se projecta pelo lado do consumo não se vislumbra pelo lado da produção. Na opinião de Mückenberger et alii (1996), a solução passa pela defesa do princípio da cidadania em estreita articulação com o princípio da igualdade, dando, assim, expressão ao conceito de "trabalhadores cidadãos". De igual modo, o reconhecimento da cidadania social e de uma noção ampla de trabalho reclama um espaço público europeu organizado no plano político. Deseja-se, como tal, um renovado equilíbrio entre o público e o privado, fundamental para evitar que, como efeito das privatizações, se transforme o cidadão num "cliente consumidor", pois "a cidadania anula-se na medida em que os cidadãos se tornam clientes e ela perde a sua dimensão pública/ política" (Mückenberger et alii, 1996, p. 150). Seguindo uma linha argumentativa próxima desta e tendo como ponto de referência o caso português, Sousa Santos sustenta que os trabalhadores não podem deixar de ser considerados eles próprios como cidadãos que trabalham e "os sindicatos só farão justiça às suas preocupações e aspirações se os reconhecerem acima de tudo pelo seu estatuto de cidadãos" exigindo-se, por isso, "uma cultura democrática de cidadania activa para além da fábrica" (Santos, 1995a, p. 139).

Segundo Malcolm Waters (1995, p. 58), é igualmente paradoxal o facto de, à medida que o consumo se universaliza - através de marcas, produtos ou referências de ordem global -, a produção localiza-se mediante critérios decorrentes de vantagens de custo. Como exemplo, é apontado o caso das Levi’s jeans que estão disponíveis para consumo global, mas que são produzidas num ambiente (local) de baixo custo de trabalho como as Filipinas. Ainda que este argumento nos pareça discutível - visto que fica por clarificar o que, efectivamente, se entende por "produção"3 -, o exemplo mencionado orienta-nos para uma situação de "dumping social”. A utilização desta ex- bora a sua orientação teórica assente na utilização de "ferramentas teóricas pós-modernas na análise de novos meios de consumo" (Ritzer, 1998, p. 1-2), em vez de uma teorização apenas baseada nos clássicos da sociologia e buscando outros exemplos para além dos restaurantes de comida rápida.

É certo que a produção pode ter lugar num local. No entanto, o seu planeamento, concepção e organização decorreram num "local maior", isto é, numa multinacional. 
${ }^{4}$ É de notar, também, como é salientado por Erickson e Kuruvilla (1994, p. 29), que a expressão "dumping social" é por vezes utilizada também para dar conta do movimento de trabalhadores de países com baixos salários para países com salários altos; cf. também Giraud (1997).

${ }^{5}$ Centrando-se, no caso alemão, na reforma sindical em curso neste país, Jürgen Hoffmann (1995, p. 111) refere que a questão da unificação europeia ocupa um lugar marginal, apesar dos esforços de cooperação com outros sindicatos nacionais, ou apesar das diferentes formas de cooperação entre trabalhadores que se procuram estimular nas zonas fronteiriças ou nas empresas pertencentes a grupos multinacionais. Esta descrença na Europa é marcada por problemas como a língua ou as diferentes estruturas de organização dos sindicatos que existem nos vários países da Europa. Porém, a principal razão reside, segundo Hoffmann, no papel central da economia alemã na União Europeia. pressão pode justificar-se em três situações distintas: em primeiro lugar, quando ocorre uma deslocação de produções de custo elevado para produções de baixo custo em países onde os salários, os benefícios sociais e os custos directos e indirectos do trabalho impostos pela legislação são claramente inferiores; em segundo lugar, quando as empresas de países com elevados custos de trabalho se vão permitindo relocalizar as suas produções, através do reforço do seu poder negocial perante a força de trabalho e do exercício de uma pressão (de sentido descendente) sobre os salários e as condições de trabalho; em terceiro lugar, quando os estados, a título individual, são tentados a seguir uma estratégia de baixos salários e anti-sindical, como forma de se fortalecerem do ponto de vista económico (cf. Mosley, 1990, p. 160) ${ }^{4}$. Um exemplo que se tornou célebre à escala europeia foi o "caso Hoover", assistindo-se nesta multinacional a uma transferência, em 1993, de uma filial francesa para a Escócia, país com salários e condições de trabalho inferiores às da França (cf. EIRR, 1993, p. 14-20).

Alguns dos exemplos invocados mostram que as mutações, tendências e efeitos que a (i)lógica global suscita e em que o movimento sindical está enleado são acentuadamente marcados por factores de ordem económica. A posição de subalternidade laboral decorrente da imposição de tais factores pode ser constatada tanto à escala nacional como à escala transnacional. Intramuros, pela observação de um "sindicalismo interno" que representa trabalhadores que auferem baixos salários. Extramuros, mas seguindo a mesma lógica, quando diferentes movimentos sindicais se posicionam junto ao limite inferior do grupo que se beneficia de elevados salários.

Mas os aspectos de ordem não económica podem igualmente influenciar as atitudes do mundo laboral. Jacoby (1995, p. 13-14) salienta que na Europa do Norte, por exemplo, o apoio prestado pelos sindicalistas de inclinação social-democrata ao processo de integração europeia constituiu uma forma de alcançar estabilidade política e solidariedade laboral na região. Ainda assim, os sindicatos alemães e escandinavos sempre procuraram mostrar que a integração europeia tem de ser olhada com prudência ${ }^{5}$, sobretudo se ela contribuir para pôr em causa os programas de bem-estar que nesses países tiveram uma notória saliência, em especial na forma como contribuíram para a realização da socialdemocracia. De modo semelhante, a razão pela qual os sindicatos canadianos se opuseram tanto ao Free Trade Agreement (Acordo de Comércio Livre, iniciado em 1989 entre os Estados Unidos da América e o Canadá) residiu no receio de que tal processo de integração poderia minar os programas sociais canadianos, cujo índice de generosidade é maior do que o americano. Por seu lado, foram ainda razões não económicas que fizeram com que, nos anos cinquenta, os sindicatos de filiação comunista se opusessem ao processo de construção europeia então iniciado, argumentando que tal processo constituía uma iniciativa anticomunista ou, mais precisamente, anti-soviética. Este sentimento de desconfiança face à construção europeia foi manifestado, no caso português (e já na década de setenta), por parte da Confederação Geral dos Trabalhadores Portu- 
gueses (CGTP), embora muito provavelmente o melhor exemplo de oposição persistente e frontal tenha sido, até março de 1999, o que envolvia a Confédération Générale du Travail (CGT) francesa, central sindical comunista que só nessa data se filiou na maior organização sindical deste continente, a Confederação Europeia de Sindicatos (CES).

\section{Da crise de indentidades...}

Mesmo que a globalização provoque, como se vem procurando mostrar, impactos desestruturadores sobre os mercados de trabalho, é curial ter em consideração que tais impactos são condicionados igualmente por diferentes instituições e tradições nacionais - estruturas sindicais específicas, acções governativas e políticas patronais concretas, etc. Com efeito, apesar das tentativas encetadas para harmonizar transnacionalmente os mercados de trabalho - como foi o caso, na Europa, da aprovação, em finais de 1989, da Carta Comunitária dos Direitos Sociais Fundamentais dos Trabalhadores ou, na América do Norte, das iniciativas de Free Trade Agreement entre os EUA e o Canadá, que seriam depois alargadas ao México, com o Nort American Free Trade Agreement (NAFTA) -, estes continuam a ser marcados por estruturas salariais específicas, programas de bem-estar diferenciados e sistemas de relações de trabalho distintos. A complexidade institucional que caracteriza os mercados de trabalho cria, assim, dificuldades na sua harmonização. Esta ideia parece reforçar o argumento de Robert Boyer, segundo o qual na "era da globalização" é preferível falar em interdependência crescente em vez de globalização. E como “o tempo das nações não acabou” é possível constatar a "resistência de modos de vida", até porque a globalização "não significa homogeneização do espaço mundial, mas, ao contrário, diferenciação de especializações" (Boyer, 1997, p. 26).

Um novo foco de identidade para o trabalho tem pois de ser redescoberto entre particularismos e especificidades. Buscar um novo foco identitário para o trabalho é, todavia, um desafio tão difícil quanto o desafio da superação do carácter ambíguo do próprio trabalho, pois é perfeitamente possível sustentar, na linha de pensamento de Marx, que o seu lado emancipatório se mistura, de forma instável, com o seu não-lado opressor. Para R. Hyman (1997, p. 521), um dos obstáculos que se colocam à construção de um projecto solidarista neste final de século reside na crescente diferenciação interna que afecta a população trabalhadora. No campo da acção sindical, a solidariedade só constitui um objectivo prioritário a alcançar porque a classe trabalhadora nunca se constituiu como um todo homogéneo. O papel de agregador de interesses desempenhado pelos sindicatos pode contemplar igualmente as perdas e não apenas os ganhos, quer se trate das relações com o capital, quer se trate das relações dentro da própria esfera do trabalho. A definição tradicional dos sindicatos enquanto associações de representação de interesses "reflectiu sistematicamente a dis- 
${ }^{6}$ No que diz respeito ao caso português, estudos recentes revelam uma quebra acentuada da sindicalização, na linha do que acontece em geral a nível mundial. Segundo a OIT (BIT, 1997, p. 252), a sindicalização em Portugal caiu para $25,6 \% \mathrm{em}$ 1995 , ou seja, para quase metade dos $51,4 \%$ registados dez anos antes (a maior quebra verificada nos países da União Europeia). Igualmente em trabalho recente, Conceição Cerdeira salienta que "o movimento sindical perde em média, anualmente, desde 19791984 a 1991-1995, cerca de 44 mil sindicalizados, ocorrendo o maior declínio na segunda metade dos anos 80: cerca de 320 mil em 1985-90, contra 200 mil em 1991-1995" (Cerdeira, 1997, p. 48. Cf. também, entre outros, Waddington, Hoffmann \& Lind, 1997 , p. 466). Por outro lado, relativamente à realidade brasileira e nas vésperas das eleições presidenciais de outubro de 1998 (que reconduziriam Fernando Henrique Cardoso ao poder), eram também pouco animadoras as notícias para os sindicatos em termos financeiros. Entre outros aspectos, o pacote legislativo de medidas proposto pelo governo de Fernando Henrique tribuição de poder existente dentro da classe trabalhadora. Aquilo que são frequentemente apresentadas como expressões de interesses gerais de classe foram tradicionalmente em grande medida representações de interesses particulares de sectores relativamente vantajosos" (Hyman, 1997, p. 517). Presentemente, este cenário evidencia sinais de actualização, pois a construção de uma identidade colectiva como "coisa" globalmente partilhada e assente numa solidariedade local, nacional e transnacional entre trabalhadores encontra-se seriamente ameaçada.

As "crises do sindicalismo" ou a "crise de sindicalismos", cujos sinais mais notórios se fazem sentir, em especial nos países centrais, a partir dos anos setenta, são o melhor exemplo da dificuldade em construir uma nova identidade para o trabalho que possa ser assumida como questão de interesse público. De forma sintética, pode dizer-se que a ausência de articulação de interesses em torno da classe operária, a crise resultante da falta de solidariedade dos militantes sindicais face à emergência do individualismo contemporâneo, o enfraquecimento das formas de actuação (luta) sindical, ou ainda a crise de representatividade social, frequentemente traduzida na quebra das taxas de sindicalização ${ }^{6}$, são alguns dos sinais dessa(s) crise(s).

A incapacidade que o sindicalismo hoje denota em cumprir a tripla função que constitui a sua essência - "representar grupos sociais (seja através dos procedimentos formais da negociação ou simplesmente exprimindo aspirações e reivindicações), contribuir para a regulação social (agregando interesses e tornando, assim, possível uma gestão dos conflitos pela negociação colectiva), organizar a solidariedade no interior do grupo representado e lutar por uma maior justiça social (redução das desigualdades, instauração de regras de direito na gestão social, desenvolvimento da participação, etc.)" (Rosanvallon, 1988, p. 22-23) - é mais um elemento revelador da sua perda de poder. Tal como sustenta George Ross (1996, p. 14), a lição que presentemente se pode retirar para o sindicalismo é, antes de mais, a de que a ligação orgânica entre sindicatos e partidos de esquerda não é mais a esperança dos que querem transformar o capitalismo. As mudanças políticas que ocorrem em cada país, associadas à globalização da economia, tornaram pouco fiáveis as alianças de outrora quase por toda a parte. Os partidos de esquerda, ainda que possam ser reformistas, determinam-se cada vez menos em função das prioridades do mundo do trabaho. Assim sendo, a salvação dos sindicatos surgiria com o crescimento do seu próprio poder. Na perspectiva de Visser (1995, p. 53-55), a força dos sindicatos mede-se por referência a três principais fontes de poder. Primeiro, o poder organizacional consiste na capacidade dos sindicatos: a) para mobilizar e recrutar membros (o que nos remete, de novo, para as taxas de sindicalização); b) para congregar o pessoal operacional, técnico e de supervisão e a produção directa e indirecta dos trabalhadores numa única organização; c) para evitar as formas de fragmentação dos sindicatos profissionais; d) para suster as divisões ideológicas; e) para evidenciar aptidão para trabalhar com distintos partidos políticos sem se tornar dependente deles ou de parte deles; f) para construir uma extensa 
organização externa com ramos ao nível da empresa e um controlo centralizado dos processos de decisão. Segundo, o poder institucional está relacionado com os laços que os sindicatos desenvolvem, através de consulta, negociação e representação, com outras organizações, como as associações de empregadores e as instituições públicas. Terceiro, o poder económico encontra-se associado aos padrões de qualificação dos membros de um sindicato, prendendo-se com a capacidade sindical para "influenciar" o mercado e o seu "sucesso" sendo tanto maior quanto maior for a organização e a protecção institucional do sindicato. Tendo presente que estas e outras formas de poder $^{7}$ conhecem graus e intensidades distintos consoante a análise efectuada em diferentes espaços nacionais, somos levados a considerar que o discurso da crise do sindicalismo se relaciona de forma instável e incómoda com o discurso do poder e que a assunção do primeiro mais não é do que um prolongamento mal sucedido do segundo.

O declínio dos corpos intermédios (testemunhado precisamente pela erosão do fenómeno sindical) pemite falar num mal-estar identitário, que não deve justificar-se apenas como um recuo do sentido da solidariedade. O malestar identitário não é produto de um desinvestimento moral em bens públicos, mas antes das profundas mutações ocorridas ao nível da relação entre o individual e o colectivo. "Durante muito tempo, a referência ao colectivo foi um meio fundamental de satisfação das necessidades individuais. Cada indivíduo tinha a impressão de que as normas sociais e as instituições o serviam e ajudavam a conquistar o seu lugar. Hoje, pelo contrário, tornou-se mais do que evidente que o futuro dos indivíduos se mostra menos ligado a um destino comum. Há cada vez menos a possibilidade de contar com uma acção colectiva para a resolução das dificuldades de cada um ou para a defesa das suas reinvindicações" (Fitoussi \& Rosanvallon, 1997, p. 22). O próprio individualismo é ambíguo pois ao mesmo tempo que constitui um factor de emancipação e de autonomia dos indivíduos, é também um factor de insegurança que faz com que cada indivíduo, por si só, tenha de gerir o seu futuro. Nestes termos, a individualização-emancipação é também uma individualizaçãofragilização (Fitoussi \& Rosanvallon, 1997, p. 18-19). Se, portanto, for verdade que a concretização da solidariedade é o caminho mais curto para a construção de uma identidade, é de admitir, então, que esta se construa com base numa solidariedade que seja sinónimo do que Valkenburg e Beukeuma (1996, p. 747-749) designam por multiformidade, termo que significa que uma pessoa deve ser capaz de pensar e de fazer coisas distintas. Ao contrário da visão tradicional da solidariedade acolhida pelo movimento sindical - que assenta no princípio de que todos os trabalhadores assalariados possuem um número de interesses comuns na base de características da sua situação de trabalho objectivamente presumida -, a norma actual é que as acções das pessoas sejam de suporte recíproco ou que, pelo menos, não causem prejuízo aos outros. Num cenário crescentemente caracterizado pelas formas de trabalho atípico, "várias formas de solidariedade são possíveis e necessárias. A visão tradicional de solidariedade permanece válida em certa medida. Contudo, já não é a
Cardoso contemplava o fim da unicidade sindical e das contribuições compulsórias dos trabalhadores para os sindicatos (cf. Público, 17/08/98).

7 Jensen, Madsen e Due (1995, p. 12-15), por exemplo, destacam, para além do poder institucional (isto é, os recursos de poder que estão directa ou indirectamente ligados a estruturas institucionais e que contemplam os acordos celebrados com as organizações de empregadores), duas outras fontes de poder sindical: o poder conflitual - traduzido na capacidade de as organizações sindicais limitarem, por um grande período de tempo, o acesso das entidades empregadoras a um tipo específico de trabalho - e o poder politico - concretizado na possibilidade de uma organização sindical exercer pressão (influência) sobre um determinado sistema político que é preponderante num ambiente de relações de trabalho. 
única e talvez não seja, provavelmente, a mais importante base para uma prática sindical" (Valkenburg \& Beukema, 1996, p. 749).

Sendo a maior organização sindical europeia - composta por 65 confederações sindicais nacionais de 28 países e por 14 federações sectoriais, num total de 59 milhões de membros (cf. ETUC, 1999, p. 2) ${ }^{-}$, a já citada CES constitui-se seguramente como a mais legítima representante dos trabalhadores europeus funcionando mesmo como grupo de pressão e actor político (cf. Goetschy, 1996, p. 258, 264). A defesa do aprofundamento da construção europeia e a consolidação da europeização sindical têm marcado a evolução da CES desde há duas décadas e meia. No entanto, também a este nível mais vasto de organização sindical têm surgido limitações. Por um lado, porque muitos sindicatos filiados na CES permanecem vinculados a perspectivas e objectivos nacionais. Por outro lado, porque a ausência de um suporte financeiro adequado proveniente das organizações filiadas fez com que esta organização ficasse muito dependente dos apoios provenientes da Comissão Europeia, tornando-se vulnerável às mutações políticas ocorridas dentro desta e, consequentemente, suscitando dúvidas sobre a "independência" da política seguida pela CES. Por último (e com ligação aos pontos anteriores), porque no seu desenvolvimento a CES foi incapaz de promover uma identidade transnacional entre trabalhadores. Assim sendo, distintos interesses e identidades persistem dentro da CES, o que leva a admitir que a identidade transnacional de trabalhadores através da acção possa resultar em oposição à integração em vez de redundar em apoio a este imperativo (cf. Waddington, Hoffman \& Lind, 1997, p. 485).

Assim, tanto a uma escala global ou regional como em diferentes escalas nacionais e contextos locais, talvez seja mais acertado falar numa identidade sindical difusa que, por esse motivo, é tão-só uma identidade parcial. Esta fragmentação identitária que enleia o trabalho é confirmada pelo caminho rápido das sociedades para o “fim da excepção salarial”. Neste cenário, podia pensar-se na já antiga figura do trabalhador imigrante, verdadeiro vendedor "livre" da força de trabalho. Os mineiros polacos em França, os mineiros shangann (moçambicanos) na África do Sul, os operários agrícolas mexicanos nos EUA, entre muitos outros, não são apenas deslocados por razões de pobreza ou catástrofe natural. Tais situações confirmam um desmembramento histórico de modos de produção locais e uma frequente dinâmica de divisão do trabalho. Por isso, as migrações de trabalho "consubstanciaram-se em mecanismos domésticos de mobilização e reprodução social e a sedentarização salarial não é senão uma das formas, provisória, de exploração dos trabalhadores" (Copans, 1997, p. 37). Perante uma "sociedade salarial como excepção", torna-se imperativo repensar o direito ao trabalho e reiventar o salariato. Historicamente, a criação de mecanismos de protecção e regulação do contrato de trabalho acabou por conferir uma certa dignidade à condição salarial. Daí que presentemente se coloque o objectivo de "reiventar formas equivalentes de protecção numa econo(1996) e Lind (1996). mia cada vez mais fragmentada" (Fitoussi \& Rosanvallon, 1997, p. 120). E 
como tivemos oportunidade de referir noutro lugar (cf. Costa, 1997, p. 255), o leque de arternativas que se colocam aos trabalhadores de uma sociedade global é cada vez mais reduzido e unidireccional. A atestá-lo está o facto de a opção "emprego" adquirir um significado fundamental, relegando para um plano cada vez mais secundário a opção "aumento mais emprego". Realizada em março de 1997, a greve europeia na Renault constituiu um exemplo revelador disso mesmo. Esta greve foi considerada por grande parte da imprensa europeia como a primeira "eurogreve" da história, com uma mobilização de cerca de 100.000 trabalhadores. Teve como pano de fundo a polémica gerada em torno da decisão do encerramento da fábrica da Renault em Vilvoorde, na Bélgica, e o consequente despedimento dos seus 3.100 trabalhadores. E não foram apenas os belgas a manifestar-se, pois centenas de camionetas levaram até Bruxelas milhares de operários, em particular franceses, igualmente ameaçados de possível desemprego devido à possibilidade de a Renault ali encerrar unidades fabris que empregam cerca de 2.700 pessoas.

Perante este diagnóstico, a orientação dos direitos sociais para um novo caminho de integração constitui-se como uma opção acertada. Aquele imperativo funcionalista encontra fundamento na luta contra a exclusão e convida-nos a aprofundar "os direitos de integração, cuja principal figura parece ser o direito à inserção". Mas este direito à integração "vai mais longe que um direito social clássico. Começa por enriquecê-lo de um imperativo moral: para além do direito à subsistência procura dar forma ao direito à utilidade social; considera os indivíduos como cidadãos activos e não só como assistidos a socorrer. A noção de integração contribui nesse sentido para definir um direito da era democrática, conjugando auxílio económico e participação social" (Fitoussi \& Rosanvallon, 1997, p. 139-140). No mesmo sentido, Mückenberger et alii (1996) sublinham que os direitos de cidadania não podem ser apenas sinónimo de privilégios, pois implicam sempre dever de solidariedade.

\section{...aos temas que se perfilam}

Na esteira de Hyman (1997, p. 529; 1998, p. 145), entendemos que qualquer projecto tendente a criar um novo modelo de "solidariedade orgânica" deve assentar no reforço da ideia de que existem diferenças e limitações ao nível da esfera laboral. O reconhecimento e o respeito pelas diferenças de interesses devem ter lugar a três níveis: entre os membros de um mesmo sindicato; entre sindicatos dentro de movimentos laborais nacionais; e entre trabalhadores em diferentes países. Mas este reconhecimento de que há limitações jamais deve ser equacionado como resignação. Nesse sentido, há hoje temas que, segundo o mesmo autor (cf. Hyman, 1997, p. 530-531; 1998, p. 145-148), preenchem a agenda de sindicalistas e devem funcionar como mecanimos de valorização e (re)afirmação identitária do trabalho, mesmo que não se esconda o seu carácter problemático. São eles a flexibilidade, a segurança e a oportunidade.

Quanto à flexibilidade pode desde logo dizer-se que não de trata de 
uma questão fácil na medida em que são alternativos e até opostos os significados que pode incorporar. A flexibilidade é uma palavra que está na moda, remetendo-nos simultaneamente para algo que é desejável e para um preço a pagar, sendo difícil conferir-lhe um significado particular face à multiplicidade de conotações que a envolvem. Em primeiro lugar, a flexibilidade significa "eliminação de rigidez: por isso, dois factores que geralmente contribuem para a criar são a deregulation e a limitação das interferências governativas; muitos incluíram nela também o aligeiramento do peso fiscal sobre empresas e indivíduos" (Dahrendorf, 1996, p. 23). Porém, a flexibilidade acabou por se traduzir no enfraquecimento dos laços que pesam sobre o mercado de trabalho: "maior facilidade na aceitação do despedimento, possibilidade de aumentar e diminuir os salários, expansão dos empregos a tempo parcial e a prazo, mudança mais frequente de trabalho, de empresas e de lugar" (Dahrendorf, 1996, p. 23-24). Independentemente das tipologias ou dimensões que este conceito incorpora (e que não cabe aqui abordar), a gestão do tempo pode eleger-se hoje como um factor que condiciona decisivamente o mundo laboral, quer no que concerne às formas reinvindicativas suscitadas em torno da redução dos diferentes tempos do trabalho (diário, semanal, anual ou de vida activa), quer no que diz respeito à ligação temporal cada vez mais inevitável entre o emprego, as actividades de lazer e a vida familiar.

Quando está em jogo uma coordenação de actividades entre vida profissional e familiar seria de esperar, por exemplo, que a flexibilidade fosse sinónimo de uma valorização da integração feminina no meio empresarial tendo em consideração que as mulheres conservam o hábito de realizar várias tarefas em simultâneo bem como de proceder a uma gestão dos tempos de trabalho e de não-trabalho ou ainda a ajudar os outros nas suas necessidades familiares. No entanto, o entendimento que as empresas fazem da flexibilidade é sinónimo de "alongamento da jornada de trabalho, às vezes com trabalho suplementar nãoremunerado, disponibilidade total por parte dos trabalhadores para responderem às exigências da 'produção' e, fundamentalmente, precarização do emprego" (Ferreira, 1998, p. 15). Citando o caso alemão, a mesma autora lembra que há empresas que só contratam homens casados cujas mulheres não tenham uma actividade fora de casa. Uma mulher que possua entre 20 a 30 anos que se candidate a um emprego é olhada pelos empregadores como uma "mãe potencial, o que na concepção de muitos empregadores significa uma trabalhadora de fraca produtividade, elevado absentismo, alheamento e falta de empenho e de flexibilidade no trabalho" (Ferreira, 1998, p. 16). A exigência colocada às trabalhadoras para que não engravidem enquanto estão em vigor os contratos de trabalho é, de resto, uma prática comum em Portugal, tanto mais que é sabido que a lei impede o despedimento de mulheres grávidas.

Uma orientação dos trabalhadores para a flexibilização do tempo de trabalho como forma de confronto com o capital deveria, pois, traduzir-se numa acrescida integração da classe trabalhadora. No caso português, a interpretação e aplicação da Lei 21/96 de 23 de julho que veio estabelecer a redu- 
ção dos períodos normais de trabalho superiores a quarenta horas por semana (conhecida por "Lei das 40 horas") não terá propriamente constituido o melhor exemplo disso, antes suscitando ou abrindo espaço para mal entendidos e interpretações que deixaram os sindicatos afectos às principais estruturas sindicais descontentes, mas não necessariamente predispostos a actuar conjuntamente contra certas violações da lei por parte das entidades patronais. Nestes termos, mesmo percorrendo apenas algumas das facetas da flexibilidade, percebe-se que é fundamental que esta questão seja agarrada pelo movimento sindical no seu todo, a começar pelas próprias estruturas sindicais nacionais, às quais deve presidir uma forte convicção nos valores de alternativa defendidos mas um igualmente forte sentido de tolerância sindical nacional. Caso não haja o devido cuidado com uma lógica de organização sindidal que promova o dinamismo e a confiança entre trabalhadores com o intuito claro de agregação de esforços no sentido do confronto externo (com o capital) não será fácil fugir à ambiguidade que o conceito dá mostras de perpetuar tanto no plano interpretativo como ao nível das práticas concretas.

Em segundo lugar, em redor da ideia de segurança também não se antevêem facilidades. A instabilidade associada à coerção do mercado está aí para o provar, pois "a mão visível das multinacionais interage com a crescente, invisível e coerciva mão do capital financeiro" (Hyman, 1997, p. 525; 1998, p. 140). Tal significa, portanto, que a insegurança é mais "segura" (porque realista) enquanto key-word de final de século. A própria ideia de estabilidade que a segurança traz consigo e que se aplica aos que ocupam um emprego (mesmo que precário) não apaga a instabilidade daqueles que estruturalmente permanecem fora do sistema, tais como os desempregados ${ }^{9}$ (de curta e longa duração), os trabalhadores migrantes, as minorias étnicas, etc.

A tentativa de superar os obstáculos decorrentes desta visão de precaridade abriu a porta, sobretudo ao nível do discurso político europeu, para o conceito de "empregabilidade", consagrado numa Cimeira Extraordinária sobre o Emprego realizada em novembro de 1997 no Luxemburgo. Grosso modo, este conceito pretende fazer passar a ideia de que, perante a constatação de uma imprevisibilidade praticamente impossível de controlar por parte dos cidadãos - de que o emprego apresenta condições de segurança numa determinada empresa ou sector -, é possível e desejável ir ao encontro de condições de controlo da vulnerabilidade do próprio mercado de trabalho, nomeadamente pela aquisição de melhores padrões de qualificação e formação ao longo da vida activa, daqui decorrendo, por conseguinte, uma maior previsibilidade, leia-se, uma maior segurança. Sem esse "elo vital a estabelecer entre a qualificação e o emprego, vide empregabilidade, a passagem à sociedade do conhecimento será fonte de novas e profundas desigualdades entre as pessoas, regiões e países" (Rodrigues, 1997). Em Portugal, por exemplo, é enorme o défice de qualificação escolar e profissional por comparação à média europeia, pois “ 65 por cento da população empregada portuguesa não dispõe de escolaridade básica, quando esta percentagem é apenas de 27 por

\footnotetext{
9 Veja-se, por exemplo, o movimento dos desempregados em França, ocorrido em janeiro de 1998. Tratou-se de um movimento de forte contestação aos actores que, situados dentro do sistema, estão investidos de capacidade de lobby. Os sindicatos aparecem como principais visados, mas para além deles também os partidos políticos, as organizações patronais e todas as organizações sociais susceptíveis de se afirmarem como "grupos de pressão".
} 
cento na média europeia" (Rodrigues, 1997). Outros dados fornecidos pelo Ministério do Trabalho e da Solidariedade confirmam que Portugal "é o parceiro europeu com uma proporção mais elevada do emprego no nível educativo baixo: 75,4\% do total. Em relação ao nível educativo médio, Portugal apresentava também em 1996 a proporção mais baixa de todos os estados-membros: 12,5\%" (Ministério do Trabalho e da Solidariedade, 1998, p. 16).

É neste contexto que se compreende a criação de estratégias europeias planeadas para o emprego com o intuito de materializar os compromissos assumidos pelos estados na Cimeira do Emprego do Luxemburgo e de dar sequência às directrizes sobre o emprego acordadas nessa cimeira. Assentando numa melhoria da empregabilidade, num desenvolvimento do espírito empresarial, num incentivo à capacidade de adaptação dos trabalhadores e das empresas e num reforço das políticas de igualdade de oportunidades, tais directrizes foram objecto de transposição para a realidade portuguesa por via da criação de um Plano Nacional de Emprego (PNE, que entrou em funcionamento em julho de 1998) destinado precisamente a elevar os níveis e a qualidade do emprego. De entre os objectivos estratégicos deste PNE salienta-se: a promoção de uma transição adequada dos jovens para a vida activa; a promoção da inserção sócio-profissional dos desempregados acompanhado do combate ao desemprego de longa duração e à exclusão; a melhoria de uma qualificação de base e profissional da população activa numa perspectiva de formação ao longo da vida; e uma gestão preventiva e acompanhamento dos processos de reestruturação empresarial. Não obstante o governo português ter considerado que foi um dos que na Europa mais lutou para a implementação do PNE, o primeiro olhar que as centrais sindicais portuguesas lançaram sobre ele foi revelador de forte descrença. Enquanto a UGT se queixava de que o projecto era limitativo no tocante às zonas-piloto abrangidas bem como em matéria de recursos humanos, técnicos e financeiros envolvidos (cf. Público, 08/04/98), a CGTP assumia uma posição ainda mais crítica, sustentando ser o Plano sinónimo da "continuação de uma política geradora de mais desemprego, com falências e encerramentos de empresas", não podendo pois o "avalizar qualquer plano que não assuma como directriz a redução do tempo de trabalho" (Público, 07/04/98).

Todavia, esta visão sindical crítica não significa que os responsáveis sindicais não se sintam alertados para a necessidade da adopção de programas de educação ou cursos de formação ao longo da vida activa de forma articulada com as estratégias patronais. A inteligência é um dos elementos que pode sustentar a estrutura organizacional dos sindicatos (cf. Hyman, 1997, p. $519 ; 1998$, p. 134), pois quanto mais as organizações sindicais dispuserem de conhecimentos especializados, de educação e recolha de informação e a souberem distribuir pela própria organização tanto mais estarão a recuperar poder (nomeadamente poder económico, para ir de novo ao encontro da classificação de Visser citada atrás). Mas, independentemente dos dispositivos institucionais ou dos objectivos de uniformidade que possam estar associados 
à "empregabilidade", a questão que, a nosso ver, não se dissolve no ar quando se invoca este conceito é a de saber até que ponto os outsiders acima citados diminuirão. É do conhecimento que os governos dos 15 da UE decidiram na Cimeira do Luxemburgo que, a partir do momento em que se encontram desempregados, os jovens terão, no espaço de seis meses, a possibilidade de frequentar cursos de formação profissional ou laboral, ou mesmo ter um novo emprego. No entanto, para os mais velhos (adultos) verifica-se que o horizonte temporal é maior - cerca de um ano -, o que significa que o foco integrativo é menor. Por outro lado, parece-nos curial que tanto os responsáveis políticos, que presentemente muito aparecem empenhados em divulgar e apoiar Planos de Emprego como o PNE português, como os patronais tenham em consideração experiências anteriores de concessão de apoios ao emprego jovem ${ }^{10}$. Mas para além da idade, a vertente sexual pode confirmar-se como sinal estrutural de exclusão social caso não se corrijam desequilíbrios em muitos sectores produtivos entre homem e mulher, como foi mencionado atrás a propósito do tema da flexibilidade. Atacar a discriminação existente entre homens e mulheres, conciliar a vida profissional e a vida familiar e facilitar a reintegração na vida activa são três elementos que os estados-membros da UE deverão ter em conta durante 1998 para promover melhorias no mercado de trabalho (cf. Commission européenne, 1997, p. 9).

Por outro, convém também lembrar que, mesmo que constitua uma orientação politicamente correcta, a defesa da qualificação está longe de apagar a desqualificação, visto que esta foi sabendo reproduzir os seus próprios prejuízos, confirmando, desse modo, o carácter estrutural da exclusão. Invocando o caso francês, Fitoussi e Rosanvallon referem mesmo que, por efeito da mundialização, se agravam "as consequências da desqualificação tendencial do trabalho não-qualificado. Assim, a taxa de desemprego dos trabalhadores qualificados em França passou de 2,5\% em 1970 para 3,5\% em 1980 e 6,0\% em 1993, no auge da recessão. Mas a taxa de desemprego dos trabalhadores não-qualificados passou, por seu lado, ao longo do mesmo período, de 3,0\% para 9,0\% e depois 20,0\%" (Fitoussi \& Rosanvallon, 1997, p. 84).

Dir-se-á, pois, que a fuga à insegurança, por meio da busca de um elo de ligação entre o emprego e a qualificação, constitui um desafio fundamental para o mundo do trabalho. No caso português, apesar de resistências verificadas, os responsáveis sindicais devem desempenhar nesse processo um papel fundamental pois só desse modo poderão transformar o tema "segurança” em algo que, usando a terminologia de Giddens (1989), supere uma simples "consciência discursiva".

Em terceiro e último lugar, a ideia de oportunidade, que Hyman associa aos objectivos de progressão na carreira e de mobilidade profissional, só possíveis no quadro de uma estrutura colectiva de oportunidades. Em nosso entender, este conceito relaciona-se muito de perto com os dois anteriores, pois constitui uma causa do primeiro - a flexibilidade - e um efeito do segundo - a segurança. A oportunidade condiciona e é condicionada, isto é, mobili-
${ }^{10}$ No caso português, um estudo do Ministério do Trabalho e da Solidariedade veio confirmar o que os sindicatos já há muito defendiam, isto é, que dos incentivos atribuídos às empresas que empregam trabalhadores com menos de 30 anos para dinamizarem o emprego jovem, apenas um terço dos casos redundou nesse efeito prático. Dos 110 milhões de contos "subtraídos" à Segurança Social entre 1986 e 1996 (pois os recursos públicos eram transferidos para o sector privado na criação de emprego por meio da isenção ou redução das contribuições para a Segurança Social), verificou-se que cerca de 30 por cento dos abrangidos ficou sem qualquer vínculo laboral e de entre os que conseguiram ficar empregados, apenas um em cada cinco ganha mais de 100.000 escudos mensais. Nestes termos, constata-se que embora tais medidas possam ter efeitos positivos na inserção social dos jovens, apenas um terço das empresas alargou os seus quadros de pessoal (cf. Público, 31/08/98). Assim sendo, a preocupação com outsiders como os desempregados de longa duração deve ganhar uma redobrada atenção. 
${ }^{11}$ A propósito deste assunto, cf. igualmente Costa (1997, p. 234, 251 e 255) e Santos (1998, p. 7 e 20).

12 Não cabe aqui recuperar desenvolvidamente tais confrontos. No entanto, as acções transnacionais em que as principais organizações sindicais (UGT e CGTP) participam sobretudo por via da filiação na CES não têm servido para acabar com os desentendimentos de ordem nacional que existem desde a formação de ambas as organizações na década de 70 e que têm a ver com diferentes concepções de sindicalismo: uma, a CGTP, marcadamente influenciada pelas orientações ideológicas dos países de Leste; a outra, a UGT, ligada, desde a sua génese, a políticas sindicais socialistas e sociais-democráticas, típicas das principais organizações dos países da Europa ocidental. Para uma discussão desse confronto sindical que parece persistir no panorama português, cf., por exemplo, Costa (1997, p. 177-185; 223-237). za interesses e actores - servindo de pretexto para a expressão de argumentos que, embora opostos (capital versus trabalho), procuram (pelo menos em teoria) eliminar a rigidez -, e é mobilizada - no momento em que a defesa da empregabilidade se impõe como apropriado móbil portador de segurança. Sendo ao mesmo tempo opções, a flexibilidade e a segurança são também, como tal, oportunidades. O que é mais importante é que a escolha entre diferentes alternativas se afaste de um projecto individual e se crie uma verdadeira estrutura de oportunidades assente num projecto colectivo que desafie tanto os empregadores como as forças de mercado. É ainda curial acrescentar que a oportunidade deve ser olhada como um sinónimo de maximização de recursos e de minimização de perdas. Todavia, no campo de acção sindical, a valorização das primeiras não tem permitido compensar as segundas, o que significa que a afirmação de um projecto sindical colectivo enquanto instrumento de oportunidade esbarra recorrentemente na mise en scène da concorrência entre trabalhadores. Uma grande conquista histórica do movimento sindical foi precisamente a redução da concorrência entre trabalhadores nos espaços nacionais, promovendo, desse modo, o entendimento e a concertação entre as principais forças sindicais. O corolário dos agreements nacionais seria o reforço de uma solidariedade transnacional entre trabalhadores. A já mencionada greve europeia da Renault foi o exemplo de uma oportunidade para fazer vingar uma acção laboral colectiva. No entanto, a concorrência entre países supera muitas vezes a solidariedade entre sindicatos, pois "a competitividade internacional de um país exerce-se forçosamente em detrimento de outros países" (Ruzza, 1996, p. 123), o que significa que o aumento de emprego num país se obtem à custa de emprego noutros países ${ }^{11}$.

Factor-chave da globalização económica, esta "onda concorrencial” não está afastada do modus vivendi dos sindicatos, podendo mesmo ser incorporada por eles no seu relacionamento mútuo. A realidade portuguesa constitui um bom exemplo do confronto que existe intramuros ${ }^{12}$, ainda que problemas semelhantes possam colocar-se entre diferentes realidades nacionais. É certo que nuns casos os sindicatos formam solidariedades, mas os países retiram-lhes boa parte ou a totalidade da sua expressão. Um exemplo. Não obstante os sinais de contestação sindical europeia, os acordos de 1996 entre a UE e Índia, Paquistão e Turquia, relativos ao acesso ao mercado de produtos têxteis, foram celebrados. Tais acordos vieram criar uma acrescida concorrência aos produtos de países como Portugal, por via do recurso a uma mão-de-obra assente em salários baixos e sem direitos sociais e sindicais. Como podia lerse num documento de uma organização sindical portuguesa do sector têxtil, "a hipocrisia de 'Bruxelas' e dos políticos que falam em solidariedade é claramente desmascarada quando se vê que na prática os objectivos das suas políticas são os de favorecer os países mais ricos e os grandes grupos económicos transnacionais em prejuízo dos mais fracos, para explorar a mão-de-obra de «escravo» e de crianças que, no caso do Paquistão, atinge milhões de pessoas que trabalham quase de graça e que ainda recentemente foi alvo de um proces- 
so pela prática de dumping social" (FESETE, 1996, p. 34). Segundo um dirigente dessa organização por nós entrevistado, o sinal de que a concorrência entre países se sobrepõe à solidariedade entre sindicatos está no facto de que "há um conjunto de países que jogam na retranca porque têm outros interesses, nomeadamente, de exportação de outros produtos para o Paquistão, para a Índia e Turquia. Toda a gente, por exemplo, diz que estes negócios de agora da abertura dos têxteis a estes países teve a ver com a exportação comunitária de telecomunicações para os mesmos (...). Os suecos, bem como outros países nórdicos e a Alemanha queriam colocar naqueles países material de telecomunicações e aqueles países disseram "Está bem! Mas se põem cá as telecomunicações a gente quer lá pôr os têxteis na Europa! Como é?..."; e eles abriram!... Portanto, estiveram-se nas tintas..."13.

Noutras situações, porém, quando os países “deixam”, parece que são os sindicatos que não querem ou não aproveitam para maximizar consensos, absorvendo, também eles, a lógica de actuação dos países. A este respeito podia recordar-se o bloqueio de estradas, em finais de 1996, dos camionistas franceses, em greve pela defesa de melhores salários e de uma reforma antecipada. Neste bloqueio, no qual se verifica que não são exclusivamente os interesses de países que estão em causa mas essencialmente reivindicações sindicais nacionais, aconteceu um extravazar das mesmas para além das fronteiras nacionais, o que, todavia, não foi sinónimo da criação de solidariedades transnacionais. Um dos camionistas portugueses apanhado no bloqueio francês viria a referir o seguinte: "Nós estamos de acordo com a greve dos camionistas franceses. Quem nos dera ter melhor salários e a reforma aos 55 anos. Mas, em Portugal, com o desemprego que há, temos que ter cuidado. Agora, os franceses deviam deixar-nos passar" (Público, 26/11/96). E perante este inconformismo os camionistas franceses viriam mesmo a acusar os camionistas portugueses de revelarem um comportamento fraco, traduzido numa ausência de consciência de classe e num abdicar do direito à greve. Noutro bloqueio semelhante realizado alguns meses mais tarde por camionistas espanhóis, ocorreram mesmo ameaças e agressões a outros camionistas que pretenderam furar tal bloqueio, acções que, na prática, constituiram igualmente formas forçadas de solidariedade sindical.

Estes e outros exemplos reforçam, a nosso ver, o carácter contraditório da globalização da economia, pois se, por um lado, se estimula, reactivamente, a constituição de estratégias de unidade sindical, por outro lado, suscita-se o surgimento de contrariedades geradoras de conflitos entre diferentes sectores do movimento operário internacional e da classe operária (cf. Ruzza, 1996, p. 125). Quando recordamos o sector automóvel constatamos o inegável impacto social da Renault, empresa que em 1898 Louis Renault permitiu ver a luz do dia. Em todo o caso, e ao contrário do que sucedeu para com os trabalhadores belgas de Vilvoorde, não foi possível observar os sindicatos franceses a promoverem acções concretas de solidariedade em favor dos trabalhadores da Renault portuguesa, quer no período em que se anunciou o
${ }^{13}$ Dirigente da FESETE (entrevista, 13/08/96, p. 35-36). 
despedimento de 600 funcionários da fábrica portuguesa de Setúbal (mesmo que com a promessa de integração dos trabalhadores noutras unidades do ramo automóvel), quer no período ex post facto. Esta constatação vale também como contestação na medida em que, por meio dela, se questiona uma vez mais o verdadeiro peso da "oportunidade" na agenda sindical.

Assim, para que a(s) oportunidade(s) não seja(m) perdida(s) é fundamental que as políticas de antagonismo social associadas à acção sindical sejam orientadas para o exterior e não para o interior da classe trabalhadora, $o$ que significa, desde logo, que a superação de rivalidades internas (de âmbito nacional) é uma condição indispensável para a edificação de solidariedades laborais externas, podendo umas e outras, por meio da maximização de uma lógica de acção colectiva, constituir importantes instrumentos de valorização da condição profissional e de dignidade de classe.

\section{Conclusão}

Estes e outros temas que aqui ficaram por abordar não devem, pois, passar despercebidos ao movimento sindical em geral, mesmo que, como se foi referindo, o seu "verso" seja revelador de perplexidades e contradições que, pelo seu realismo, enfraquecem as mais do que legítimas ambições de organização e renovação da actividade sindical. Como é prognosticado por alguns, nos tempos que se avizinham "será cada vez mais raro para um sindicalista ter diante de si um decisor real. O interlocutor patronal não será mais do que o responsável por um poder geograficamente inacessível..." (Bouchet, 1997, p. 34). Dirse-ia mesmo, como Milton Santos (1993, p. 18), que é por meio do espaço que, na sua forma mais perversa, a globalização "empobrece e aleija".

Nestes termos, um requisito para superar os actuais focos temerários de identidade sindical e contribuir para a emergência de um verdadeiro sindicalismo europeu não passará propriamente pela solução utópica de resolver todas as contradições sindicais nacionais (cf. Hege, 1997, p. 512), mas sim pelo reconhecimento sério da importância do confronto entre diferentes identidades sindicais nacionais, ou não fosse, como sustenta Sousa Santos (1998, p. 36), esta necessidade de reconhecer no próprio polimorfismo do trabalho uma condição importante da sua redescoberta democrática.

Recebido para publicação em outubro/1998 
ABSTRACT: Based on samples of the European trade union reality, this article intends to develop, in the first place, a synthesis of some of the contemporary changes occurring in world labour. Secondly, it reappraises some of the characteristic elements of the present day crisis of trade unions. These features have hindered the creation of a cohesive European trade union identity. The paper also recovers themes around which alternative future challenges can be thought and which can help maximise a (re)assertion of labour identity.

\section{REFERÊNCIASBIBLIOGRÁFICAS}

AARON, Henry J. et alii. (1995) Preface to the studies on integrating national economies. In: KAHLER, Miles (org.). International institutions and the political economy of integration. Washington, The Brookings Institution, p. xi-xxiv.

Bouchet, Hubert. (1997) En attendant l'Europe sociale. Manière de Voir, Paris, 35: 33-34.

BIT (Bureau International du Travail). (1997) Le travail dans le monde: relations professionelles, démocratie et cohésion social, 1997-98. Genève.

Boyer, Robert. (1997) Les mots et les réalités. In: Cordellier, Serge \& Doutaut, Fabienne (orgs.) Mondialisation, au-delá des mythes. Paris, La Découverte, p. 13-56.

CERDEIRA, Conceição. (1997) A sindicalização portuguesa de 1974 a 1995. Sociedade e Trabalho (Revista do Ministério para a Qualificação e o Emprego), 1: 46-53.

COMMISSION EUROPÉENNE. (1997) Sommet sur l'emploi, 20-21 novembre 1997. Emploi \& affaires sociales.Bruxelles, Commission européenee.

Copans, Jean. (1997) Vers la fin de l'exception salarial. Manière de Voir, Paris, 35: 36-37.

Costa, Hermes Augusto. (1997) Os desafios da globalização ao sindicalismo: contributos para uma perspectiva portuguesa. Coimbra, $280 \mathrm{p}$. Dissertação (Mestrado). Faculdade de Economia da Universidade de Coimbra.

DAHRENDORF, Ralf. 1996. A quadratura do círculo: bem-estar económico, coesão social e liberdade política. Lisboa, Edições 70.

EIRR (European Industrial Relations Review). (1993) The Hoover affair and the social dumping. EIRR, London, 230: 14-20.
UNITERIMOS:

trade unionism, globalization, trade union identities. 
ERICKSON, Christopher L. \& KuRuviLla, Sarosh. (1994) Labor costs and the social dumping debate in the European Union. Industrial and Labor Relations Review, Cornell University, 48 (1): 28-47.

. (1995) Labor cost incentives for capital mobility in the European Community. In: JACOBY, Sanford M. (org.). The Workers of Nations. Industrial Relations in a Global Economy. Oxford, Oxford University Press, p. 35-53.

ETUC. (1999) ETUC actions and objectives. Artigo disponível na internet: www.etuc.org./info, p. 1-3.

FERREIRA, Virgínia. (1998) As mulheres em Portugal: situação e paradoxos. Oficina do CES, Coimbra, 119: 1-29.

FESETE. (1996) Fortalecer a organização. Defender o emprego, o salário e os direitos. Porto (Sétimo Congresso).

Fitoussi, Jean-Paul \& Rosanvallon, Pierre. (1997) A nova era das desigualdades. Lisboa, Celta.

GAY, Paul du. (1996). Consumption and identity at work. Londres, Sage.

Giddens, Anthony. (1989) A constituição da sociedade. São Paulo, Martins Fontes.

GIRAUd, Pierre-Noël. (1997) Mondialisation, emploi et inégalités. In: CoRDELLIER, Serge \& Doutaut, Fabienne (orgs.). Mondialisation, au-delá des mythes. Paris, La Découverte, p. 101-115.

Goetschy, Janine. (1996) The European Trade Union Confederation and the construction of European unionism. In: LEISINK, P.; VAN LEEMPUT, J.; VILROKX, J. (orgs.). The chalenges to Trade Unions in Europe: innovation or adaptation. Cheltenham, Edward Elgar, p. 253-265.

Grupo de Lisboa. (1994). Limites à competição. Lisboa, Publicações Europa-América.

Hege, Adelheide. (1997) Trade unions in crisis - a European renaissance? Transfer - European Review of Labour and Research, Brussels, 3(3): 498-514.

Hoffmann, Jürgen. (1995) Trade union reform in Germany: some analytical and critical remarks concerning the current debate. Transfer European Review of Labour and Research, Brussels, 1(1): 98-113.

HyMAn, Richard. (1997) Trade unions and interest representation in the context of globalisation. Transfer - European Review of Labour and Research, Brussels, 3(3): 515-533.

. (1998) La représentation syndicale des intérêts dans une Europe en mutation. Sociologie du Travail, Paris, 2: 129-149.

JACOBY, Sanford M. (1995) Social dimension of global economic integration. In:___ (org.). The workers of nations. Industrial relations in a global economy. Oxford, Oxford University Press, p. 3-29. 
Jensen, C. S.; Madsen, J. S. \& Due, J. (1995) A role for pan-European trade union movement? - possibilities in European IR-regulations. Industrial Relations Journal, London, 26(1): 4-18.

Lind, Jens. (1996) Trade Unions: social movement or welfare apparatus? In: Leisink, P.; VAn LeEmput, J. \& VILROKX, J. (orgs.). The chalenges to Trade Unions in Europe: innovation or adaptation. Cheltenham, Edward Elgar, p. 105-120.

Ministério do Trabalho e da Solidariedade. (1998) Plano Nacional de Emprego: texto integral (versão preliminar para consulta à Assembleia da República e à Comissão Permanente de Concertação Social). Lisboa.

Mosley, Hugh. (1990) The social dimension of european integration. International Labour Review, London, 129(2): 147-164.

MüCKenberger et alii. (1996) Manifeste pour une Europe sociale. Paris, Desclée de Brouwer.

RITZER, George. (1993) The McDonaldization of society: an investigation into the changing character of contemporary social life. London, Pine Forge Press. . (1998) The MacDonaldization Thesis. London, Sage.

Rodrigues, Maria João. (1997) Portugal com mais qualificação. Expresso, Lisboa, 29/11, p.17.

Rosanvallon, Pierre. (1988) La question syndicale. Paris, Calmann-Lévy.

Ross, George. (1996) La grande révolte française contre l'europe libérale. Noblesse et misères du syndicalisme. Le Monde Diplomatique, Paris, 43(502): 14-15, janeiro.

Ruzza, Renato di. (1996) L'internationalisation de l'économie et la crise du syndicalisme. L'Homme et la Société, Paris, (121-122): 117-130.

SANTOS, Boaventura de Sousa. (1995a) Teses para renovação do sindicalismo em Portugal, seguidas de um apelo. Vértice, Lisboa, 68: 132-139. (1995b) Toward a new common sense: law, science and politics in the paradigmatic transition. London/New York, Routledge.

- (1998) Reinventar a democracia: entre o pré-contratualismo e o pós-contratualismo. Oficina do CES, Coimbra, 107: 1-53.

SANTOS, Milton. (1993) A aceleração contemporânea: tempo mundo e espaço mundo. In: et alii (orgs.). O novo mapa do mundo: fim de século e globalização. São Paulo, Hucitec, p. 15-22.

VALKENBURG, Ben. (1996) Individualization and solidarity: the challenge of modernization. In: Leisink, P. ; VAN LeEmpUt, J. \& VilRoKX, J. (orgs.). The chalenges to Trade Unions in Europe: innovation or adaptation. Cheltenham, Edward Elgar, p. 89-104. 
Valkenburg, Ben \& Beukema, Leni. (1996) The organisation of flexibility. Atypical jobs as a challenge for the modernization of trade unions. Transfer-European Review of Labour and Research, Brussels, 2(4): 738-754.

VISSER, Jelle. (1995) Trade Unions from a comparative perspective. In: VAN RuYsSEVEldT, Joris; HuISKAMP, Rien \& VAN Hoof, Jacques (orgs.). Comparative industrial \& employment relations. London, Sage, p. 37-67.

Waddington, J.; Hoffmann, R. \& Lind, J. (1997) European trade unionism in transition? A review of issues. Transfer-European Review of Labour and Research, Brussels, 3(3): 464-497.

W ATERS, Malcolm. (1995) Globalization. London, Routledge.

WeBer, Max. (1990) A ética protestante e o espírito do capitalismo. Lisboa, Presença.

ZoLL, Rainer. (1996) Modernization, Trade Unions and solidarity. In: LEISINK, P. ; VAn LeEMPUT, J. \& VILROKX, J. (orgs.). The chalenges to Trade Unions in Europe: innovation or adaptation. Cheltenham, Edward Elgar, p. 77-87. 